Exercise Physiology

\title{
Biomarker responses of cardiac oxidative stress to high intensity interval training in rats
}

\author{
Lúcio Marques Vieira-Souza $^{1}$ (D), Jymmys Lopes dos $\operatorname{Santos}^{1}$ (D), Anderson Carlos Marçal ${ }^{1}$ (D), \\ Fabrício Azevedo Voltarelli ${ }^{2}$ (D), Felipe José Aidar $^{1}$ (D), Rodrigo Miguel-dos-Santos ${ }^{3}$ (D), \\ Roas de Araújo $\operatorname{Costa}^{3}$ (D), Dihogo Gama de $\operatorname{Matos}^{1}$ (D), Sandra Lauton Santos ${ }^{3}$ (D), \\ Silvan Silva de Araújo ${ }^{1}$ \\ ${ }^{1}$ Universidade Federal de Sergipe, Programa de Pós-Graduação em Educação Física, São \\ Cristóvão, SE, Brasil; ${ }^{2}$ Universidade Federal de Mato Grosso, Programa de Pós-Graduação em \\ Ciências da Saúde, Cuiabá, MT, Brasil; ${ }^{3}$ Universidade Federal de Sergipe, Programa de Pós- \\ Graduação em Ciências Fisiológicas, São Cristóvão, SE, Brasil.
}

Associate Editor: Camila de Moraes. USP/Ribeirão Preto, SP, Brasil.

\begin{abstract}
Aim: The present study aimed to verify the cardiac oxidative stress biomarker responses to high-intensity interval training (HIIT) in rats. Methods: Sixteen male Wistar rats weighing 250 to $300 \mathrm{~g}$ were equally divided into two groups ( 8 animals/group): sedentary control (SC) and trained group (HIIT). The exercise protocol consisted of highintensity swimming (14\% of body weight, $20 \mathrm{~s}$ of activity with $10 \mathrm{~s}$ of pause performed 14 times) which was performed for 12 consecutive days. Results: The cardiac tissue concentrations of malondialdehyde and carbonylated proteins showed no significant changes; on the other hand, hydroperoxide levels were higher in the HIIT group than in the SC group. The activities of superoxide dismutase, catalase, and glutathione peroxidase enzymes and the levels of reduced glutathione and sulfhydryl remained unchanged. Conclusion: It is possible to conclude that short-term high-intensity interval training induces changes in the cardiac oxidative stress biomarker but with no effect on the antioxidant enzymes.
\end{abstract}

Keywords: physical training, lipid peroxidation, heart, HIIT, swimming.

\section{Introduction}

High-intensity interval training (HIIT) is characterized by brief and repeated episodes of vigorous activity (approximately $85 \%-100 \%$ of the maximal oxygen uptake $\left.\left[\mathrm{VO}_{2 \max }\right]\right)$ followed by short periods of passive or active rest with exercises ${ }^{1-3}$. HIIT is considered a promising method for the reduction of cardiometabolic risk factors $^{4,5}$. Oxidative stress is defined as the imbalance between reactive oxygen species ROS production and intracellular antioxidant defense capacity ${ }^{6-10}$. The production and exacerbated release of ROS generated by physical exercise can disrupt intracellular redox homeostasis ${ }^{11}$, which can lead to protein oxidation, lipid peroxidation, and DNA damage ${ }^{12}$ as well as lesions in cardiac cells ${ }^{10}$. As a consequence, cellular responses to significant unrepaired damage can lead to apoptosis or senescence, contributing to the onset of cardiovascular diseases and, in some cases, metabolic syndrome ${ }^{13-20}$.

There is already evidence that HIIT can induce less membrane peroxidation, and greater competence in the antioxidant system, reduction in central mediators of necroptosis induced by myocardial infarction, in addition to cardioprotection against ischemia-reperfusion injury ${ }^{21}$ and the expression of cardioprotective proteins in a similar way to continuous exercise ${ }^{22}$. In this sense, the control of the training load is fundamental for the achievement of your specific objectives, among them, the improvement of performance. Therefore, the imbalance between volume, intensity, and density in the training session, an increase in the concentration of ROS is visible, which can lead to oxidative stress. Thus, this study verified the responses of cardiac oxidative stress biomarkers to training in rats. The hypothesis is that HIT can prevent the occurrence of exacerbated oxidative stress in the cardiac tissue.

\section{Methods}

\section{Animals and experimental groups}

Sixteen male Wistar rats (Rattus norvegicus) weighing 250 to $300 \mathrm{~g}$ and 60 days of age at the beginning of the experiment were kept under normal environmental conditions with a temperature of $24^{\circ} \mathrm{C} \pm 2{ }^{\circ} \mathrm{C}$ and a light-dark cycle of $12 \mathrm{~h}$, with free access to filtered water and standard commercial diet (Labina, Purina ${ }^{\circledR}$ ). The animals were 
randomly allocated to two experimental groups $(\mathrm{n}=8 /$ group), sedentary control group (CS), and trained group (HIIT), and kept in collective cages (4 animals/cage). All procedures were approved by the Ethics Committee for Animal Use at the Federal University of Sergipe (Process number 15/2017) and followed the Guidelines of the Brazilian College of Animal Experiments (COBEA).

\section{Adaptation to water}

The animals were acclimated and adapted to the liquid environment at a temperature of $25{ }^{\circ} \mathrm{C} \pm 1{ }^{\circ} \mathrm{C}$ in a cylindrical tank of $80 \mathrm{~cm}$ depth and $80 \mathrm{~cm}$ diameter ${ }^{17}$. During the first week, only a 10 min adaptation was performed in the water at a depth of $10 \mathrm{~cm}$. In the subsequent two weeks, the animals had a lead overload (small bags of cotton cloth and Velcro ${ }^{\circledR}$ ) attached to the chest for 10 days; the overloads used were equivalent to $0 \%, 1 \%$, and $2 \%$ of the body weight, and each animal was subjected to $10 \mathrm{~min}$ of swimming exercise with $30 \mathrm{~s}$ of swimming and $30 \mathrm{~s}$ of rest between the series, totaling 10 series. It is important to note that the adaptation period was not capable of inducing possible physiological changes due to the low intensities used $^{17,18}$.

\section{Physical training}

Physical training was performed according to a protocol adapted from the study by Terada et al. ${ }^{23}$. The animals, which were submitted to overloads equivalent to $14 \%$ of body weight, according to the authors this load is sufficient to superimpose an intensity of $80 \%$ of the animals' VO2max, also considered to be of high intensity ${ }^{24,25}$ The rats performed a $20 \mathrm{~s}$ swimming session, 14 times. Between each repetition, the animals were allowed a rest of $10 \mathrm{~s}$. All rats swam in tanks at a water depth of $60 \mathrm{~cm}$, for 12 continuous days.

\section{Euthanasia and preparation of tissues}

Twenty-four hours after the end of the last physical training session, the animals were anesthetized with ketamine/xylazine $(75 \mathrm{mg} / \mathrm{kg}+10 \mathrm{mg} / \mathrm{kg}$ i.p) followed by euthanasia via bleeding under anesthesia. Then, the heart was removed, washed three times with $1.15 \%$ potassium chloride $(\mathrm{KCl})$ solution, dried, weighed, and stored in a biofreezer at $-80^{\circ}$ for further analyses of oxidative stress biomarkers.

\section{Biochemical analyses}

Lipoperoxidation products were measured in two ways: a) concentration of lipid hydroperoxides (HPx) by the oxidation technique of xylenol orange, in which oxidation of ferrous ion $\left(\mathrm{Fe}^{2+}\right)$ into ferric ion $\left(\mathrm{Fe}^{3+}\right)$ occurs under acidic conditions; b) concentration of thiobarbituric acid reactive substances ${ }^{26}$. The concentration of carbonylated proteins in assays was determined by the technique of Lowry et al. ${ }^{27}$, which quantified the concentrations of proteins in the samples by comparison with a standard curve obtained from bovine serum albumin at different concentrations.

The activity of the superoxide dismutase enzyme (SOD) was determined by the capacity of the tissue enzyme to dismutase superoxide anions derived from the pyrogallol autoxidation and their reaction, reducing bromide 3-(4,5-dimethylthiazol-2-yl)-2,5-diphenyltetrazolium and forming formazan crystals ${ }^{28}$. Catalase (CAT) activity was determined by the hydrogen peroxide $\left(\mathrm{H}_{2} \mathrm{O}_{2}\right)$ degradation rate according to the standard protocol previously described by Nelson and Kiesow ${ }^{29}$. The activity of glutathione peroxidase enzyme (GPx) was evaluated by NADPH oxidation, as described by Paglia and Valentine $^{30}$. The activity of the glutathione reductase enzyme was assessed according to the method of Carlberg and Mannervik ${ }^{31}$. The determination of sulfhydryl groups was performed by the reaction between 5'5-dithio-bis-2-nitrobenzoic acid and free sulfhydryl of the cysteine side chain $^{32}$.

\section{Statistical analyses}

Data are expressed as mean \pm standard deviation. Data normality was tested by the Shapiro-Wilk test. Nonpaired Student's t-tests were used to evaluate the differences between the groups. P-values $<0.05$ were considered statistically significant. For all of these procedures, the statistical software GraphPad Prism version 7.0 (GraphPad Software, San Diego, CA, USA) was used.

\section{Results}

Regarding the cardiac oxidative stress biomarkers (Table 1), there was a significant increase for the HIIT group in the HPx levels when compared to the CS group. Regarding antioxidant defense, there was no change in any of the levels of MDA and PC parameters evaluated between the groups (Table 2).

\section{Discussion}

The present study verified the effect of HIIT on the cardiac oxidative stress responses in rats. The study showed that consecutive HIIT sessions caused an increase in HPx levels.

Table 1 - Effects of high intensity interval training for 12 days on oxidative stress markers hydroperoxides (HPX), malondialdehyde (MDA), and carbonylated proteins (PC) in cardiac tissues from rats.

\begin{tabular}{lccc}
\hline & CS $(\mathbf{n}=\mathbf{0 8})$ & HIIT $(\mathbf{n}=\mathbf{0 8})$ & p (value) \\
\hline HPX $(\mu M L)$ & $3.288 \pm 0.2594$ & $5.988 \pm 0.5595$ & 0.0006 \\
MDA $(\mathrm{nmol} / \mathrm{mL})$ & $8.386 \pm 0.5837$ & $8.694 \pm 0.6250$ & 0.07 \\
PC $(\mathrm{nmol} / \mathrm{mL})$ & $208.2 \pm 10.62$ & $217.0 \pm 9.377$ & 0.85 \\
\hline
\end{tabular}

Note: $\mathrm{CS}=$ sedentary control group and HIIT $=$ trained group. Data are presented as mean \pm SEM. Student's t-test. $(\mathrm{p}<0.05)$. 
Table 2 - Effects of high intensity interval training for 12 days on enzymatic antioxidant activity superoxide dismutase (SOD), catalase (CAT), glutathione peroxidase (GPx) and glutathione reductase (GR), and non-enzymatic total sulfhydryl (SH) in cardiac tissues from rats.

\begin{tabular}{lccc}
\hline & CS (n= 08) & HIIT (n=08) & $\boldsymbol{p}$ (value) \\
\hline SOD (U/mg protein) & $0.1265 \pm 0.01760$ & $0.1661 \pm 0.03506$ & 0.33 \\
CAT (U/mg protein) & $0.02038 \pm 0.003845$ & $0.03225 \pm 0.005864$ & 0.11 \\
GPx (U/mg protein) & $0.8525 \pm 0.1435$ & $0.83 \pm 0.127$ & 0.91 \\
GR $(\mu \mathrm{mol})$ & $1.819 \pm 0.632$ & $1.378 \pm 0.2635$ & 0.53 \\
SH $(\mathrm{nmol} / \mathrm{mL})$ & $208.2 \pm 10.62$ & $217.0 \pm 9.37$ & 0.54 \\
\hline
\end{tabular}

Note: $\mathrm{CS}=$ sedentary control group and HIIT $=$ trained group. Data are presented as mean \pm SEM. Student's t-test. $(\mathrm{p}<0.05)$.

Swimming HIIT was performed using a $14 \%$ load. The intensity of the training was defined by the load test, swimming with a load above $6 \%$ of the bodyweight of the animal is considered to be high-intensity exercise ${ }^{19}$. Variations of intensity, type, and duration of exercise directly influence the production of ROS, and consequently, the oxidative damage caused by it. High-intensity exercise has been shown to cause higher lipid oxidation in the liver, muscle, and blood ${ }^{33}$. During the contractile activity, an intracellular increase of $\mathrm{O}_{2}{ }^{\bullet}$, hydrogen peroxide $\left(\mathrm{H}_{2} \mathrm{O}_{2}\right)$, and nitric oxide occur. It is suggested that the action of the enzyme NADPH oxidase in the plasma membrane, cellular cytosol, and sarcoplasmic reticulum in the skeletal and cardiac muscle and also in the localized transverse tubules of the skeletal muscle is the main source of free radical production associated with physical exercise 9 .

Since HPx is considered a specific and direct biomarker of lipid peroxidation, the higher HPx concentrations in the HIIT group compared SC group in the present study show that this type of training, associated with short recovery periods, can generate adaptations in cardiac tis$\mathrm{sue}^{34,35}$ as well as cause structural remodeling of the cell membrane and its lipoproteins ${ }^{23}$, both resulting from the momentary hypoxia induced by HIIT. Casuso et al. ${ }^{36}$ found a decrease in the plasma HPx levels in swimmers subjected to hypoxia compared with those maintained under normal conditions. Some studies indicate that the cardioprotective effects of moderate to severe exercise can be attributed to a decrease in vascular inflammation and oxidative damage ${ }^{4}$, confirming previous data on blood plasma ${ }^{37}$. Increases in serum levels of aspartate aminotransferase and alanine aminotransferase enzymes following damage to tissues like the heart increases the levels of some markers, such as malondialdehyde (MDA; an authentic index of oxidative stress), and decreases the levels of antioxidant enzymes such as SOD, GPx, and $\mathrm{CAT}^{38}$. In the present study, there were no significant alterations in MDA levels in the cardiac tissue of rats. On the other hand, Freitas et al. ${ }^{39}$ demonstrated a reduction of this lipoperoxidation biomarker in rats submitted to 36 running sessions on a treadmill, unlike the present study which used the swimming exercise. Thus, we cannot rule out that the protocol-dependent design may have generated divergent results among studies. On the other hand, in a study involving humans, Tauler et al. ${ }^{40}$ measured both plasma MDA and lymphocyte protein carbonyl levels following a mountain stage cycling protocol. They reported a significant increase in both indices of oxidative stress.

Rosa-Lima et al. ${ }^{12}$ emphasized that protein oxidation can cause cell death, and carbonylated proteins are indirect markers of protein damage ${ }^{41}$. Oxidative damage can have a devastating effect on the structure and activity of proteins and can even lead to cell death. Amino acids containing cysteine and methionine are particularly susceptible to ROS and reactive chlorine species, which can damage proteins ${ }^{42}$. In the present study, there were no significant changes in the carbonylated proteins in any of the experimental groups, denoting that the HIIT protocol used did not promote oxidative damage in the cardiac tissue. HIIT has been an important protocol of signaling to a multitude of target cells allowing aerobic adaptations during the short-term, further than the traditional endurance training ${ }^{43}$. Some studies have reported that endurance training in rats may attenuate the natural loss of protein but not increase the aerobic capacity in comparison with the baseline ${ }^{44}$.

Exercise stimulates the production of ROS in tissues and blood due to large increases in oxygen uptake, while ROS are formed during physical stress, the antioxidant system improves the endogenous enzymes ${ }^{45}$. Azizbeigi et al. $^{46}$ reported that high-intensity exercise strengthens the defensive system of erythrocytes against free radical damage. The results obtained in the present study did not indicate changes in the cardiac tissue concentrations of sulfhydryl groups in response to HIIT as in the activity of antioxidant enzymes, corroborating the findings of de Araújo et al. ${ }^{43}$ and Songstad et $\mathrm{al}^{47}$, who subjected rats to high-intensity training with water jumping and treadmill running, respectively. The antioxidant enzyme levels remained unchanged significantly in relation to control, showing an insignificant disturbance of ROS.

It is important to note that the present study investigated only the effects of HIT on the cardiac oxidative stress markers in rats, with the possible limitation of the use of the swimming model for HIIT. Hence, it is suggested to use other types of ergometers such as water jumping or ladder climbing for comparison purposes. 


\section{Conclusion}

Taken together, the results of the present study suggest that short-term HIIT induces changes in the cardiac oxidative stress biomarker responses without affecting the antioxidant enzymes analyzed.

\section{References}

1. Slusher AL, Patterson VT, Schwartz CS, Acevedo EO. Impact of high-intensity interval exercise on executive function and brain-derived neurotrophic factor in healthy college-aged males. Physiol Behav. 2018;191:116-22.

2. Haram PM, Kemi OJ, Lee SJ, Bendheim MØ, Al-Share QY, Waldum HL. Aerobic interval training vs. continuous moderate exercise in the metabolic syndrome of rats artificially selected for low aerobic capacity. Cardiovasc Res. 2009;81:723-32.

3. Gillen JB, Martin BJ, MacInnis MJ, Tarnopolsky MA, Gibala MJ. Twelve weeks of sprint interval training improves indices of cardiometabolic health similar to traditional endurance training despite a fivefold lower exercise volume and time commitment. PLoS One. 2016;11: e0154075.

4. Batacan RB Jr, Duncan MJ, Dalbo VJ, Connolly KJ, Fenning AS. Light-intensity and high-intensity interval training improve cardiometabolic health in rats. Appl Physiol Nutr Metab. 2016;41(9):945-52. PMID: 27523646.

5. Cassidy S, Thoma C, Houghton D, Trenell MI. High-intensity interval training: a review of its impact on glucose control and cardiometabolic health. Diabetologia. 2017;60 (1):7-23. PMID: 27681241; PMCID: PMC6518096.

6. Groussard C, Maillard F, Vazeille E, Barnich N, Sirvent P, Otero YF, et al. Tissue-specific oxidative stress modulation by exercise: A comparison between MICT and HIIT in an obese rat model. Oxid Med Cell Longev. 2019;1965364.

7. Balci SS, Pepe H. Effects of gender, endurance training and acute exhaustive exercise on oxidative stress in the heart and skeletal muscle of the rat. Chin J Physiol. 2012;55 (4):236-44.

8. Ballman C, Graham M, Bridget PD, Slivka CJ, Hailes W, Quindry J. Exercise-induced oxidative stress and hypoxic exercise recovery. Eur J Appl Physiol. 2014;114:725-33.

9. Parker L, Trewin A, Levinger I, Shaw CS, Nigel K. Exercise-intensity dependent alterations in plasma redox status do not reflect skeletal muscle redox-sensitive protein signaling. J Sci Med Sport. 2017;10:1016.

10. Powers SK, Jackson MJ. Exercise-induced oxidative stress: cellular mechanisms and impact on muscle force production. Physiol Rev. 2008;88(4):1243-76.

11. Silva FB, Romero WG, Carvalho ALRA, Souza GAA, Claudio ERG, Abreu GR. Effects of treatment with chemotherapy and/or tamoxifen on the biomarkers of cardiac injury and oxidative stress in women with breast cancer. Medicine. 2017;96(47): e8723.

12. Rosa-Lima FL, Lannes L, Viana-Gomes D, Pierucci AP, Salerno VP. Protein carbonyl levels correlate with performance in elite field hockey players. Appl Physiol Nutr Metab. 2015;40(7):683-8.
13. Jiji RS, Kramer CM, Salerno M. Non-invasive imaging and monitoring cardiotoxicity of cancer therapeutic drugs. J Nucl Cardiol. 2012;19:377-88.

14. Floc'h N, Kolodziejski J, Akkari L, Simonin Y, Ansieau S, Lassus, P. Modulation of Oxidative Stress by Twist Oncoproteins. PLoS ONE. 2013;8(8):e72490.

15. Jenni-Eiermann S, Jenni L, Smith S, Costantini D. Oxidative Stress in Endurance Flight: An Unconsidered Factor in Bird Migration. PLoS ONE. 2014;9(5):e97650.

16. Maruoka H, Fujii K, Inoue K, Kido S. Long-term effect of ubiquinol on exercise capacity and the oxidative stress regulation system in SAMP1 mice. J Phys Ther Sci. 2014;26:367-71.

17. Contarteze RVL, Manchado FB, Gobatto CA, Mello MAR. Biomarkers of stress in rats exercised in swimming at intensities equal and superior to the maximal stable lactate phase. Braz J Sport Med. 2007;13(3):169-74.

18. Voltarelli F, Gobatto C, Mello M. Determination of anaerobic threshold in rats using the lactate minimum test. Braz $\mathrm{J}$ Medical Biol Res. 2002;35:1389-94.

19. Ramos-Filho D, Chicaybam G, de-Souza-Ferreira E, Casimiro-Lopes G, Galina A. High-intensity interval training (HIIT) induces specific changes in respiration and electron leakage in the mitochondria of different rat skeletal muscles. Plos One. 2015;10(6): e0131766.

20. Maillard F, Vazeille E, Sauvanet P, Sirvent P, Combaret L, Sourdrille A, et al. High-intensity interval training promotes total and visceral fat mass loss in obese Zucker rats without modulating gut microbiota. PLoS One. 2019;9;14(4): $\mathrm{e} 0214660$.

21. Ghardashi AA, Gaeini A, Rakhshan K, Naderi N, Darbandi AA, Aboutaleb N. Targeting necroptotic cell death pathway by high-intensity interval training (HIIT) decreases the development of post-ischemic adverse remodeling after myocardial ischemia/reperfusion injury. J Cell Commun Signal. 2019;13(2):255-67.

22. Mostafa S, Javad N, Yashar Z, Mojtaba HS, Babak HM. Comparing High-Intensity Interval Training (HIIT) and Continuous Training on Apelin, APJ, NO, and Cardiotrophin-1 in Cardiac Tissue of Diabetic Rats. J Diabetes Res. 2020;1472514.

23. Terada S, Yokozeki T, Kawanaka K, Ogawa K, Higuchi M, Tabata I. Effects of high-intensity swimming training on GLUT-4 and glucose transport activity in rat skeletal muscle. J Applied Phys. 2001;90:2019-24.

24. Cunha RR, Cunha VNR, Segundo PR, Moreira SR, Kokubun E, Simões HG. Determination of the lactate threshold and maximal blood lactate steady state intensity in aged rats. Cell Biochem Function. 2009;27(6):351-57.

25. Araujo GG, Papoti M, Delbin MA, Zanesco A, Gobatto CA. Physiological adaptations during endurance training below anaerobic threshold in rats. Eur J Appl Physiol. 2013;113:1859-70.

26. Bose R, Sutherland GR, Pinsky C. Biological and methodological implications of prostaglandin involvement in mouse brain lipid peroxidation measurements. Neurochem Res. 1989;14(3):217-20.

27. Lowry OH, Rosebrough NJ, Farr AL, Randall RJ. Protein measurement with the Folin phenol reagent. J Biol Chem. 1951;265-75. 
28. Madesh M, Balasubramanian KA. Microtiter plate assay for superoxide dismutase using MTT reduction by superoxide. Indian J Biochem Biophys. 1998;35:184-8.

29. Nelson DP, Kiesow LA. Enthalpy of decomposition of hydrogen peroxide by catalase at $25^{\circ} \mathrm{C}$ (with molar extinction coefficients of $\mathrm{H}_{2} \mathrm{O}_{2}$ solutions in the UV). Anal Biochem. 1972;49:474-8.

30. Paglia DE, Valentine WN. Studies on the quantitative and qualitative characterization of erythrocyte glutathione peroxidase. J Lab Clin Med. 1967;70:158-69.

31. Carlberg I, Mannervik B. Glutathione Reductase. Methods Enzymol. 1985:113:485-90.

32. Faure P, Lafond JL. Measurement of plasma sulfhydryl and carbonyl groups as a possible indicator of protein oxidation. In: Analysis of Free Radicals in Biological Systems. Basel, Birkhäuser; 1995. p. 237-48.

33. Gibala MJ, Little JP, MacDonald MJ, Hawley JA. Physiological adaptations to low volume, high-intensity interval training in health and disease. J Physiol. 2012;590(5):107784.

34. Gomez-Cabrera MC, Domenech E, Romagnoli M, Arduini A, Viña J. Oral administration of vitamin $\mathrm{C}$ decreases muscle mitochondrial biogenesis and hampers training-induced adaptations in endurance performance. Amer J Clinical Nut. 2008;87(1):142-49.

35. Ristow M, Birringer M, Kiehntopf M, Zarse K, Oberbach A, Klo N, Blu M. Antioxidants prevent health-promoting effects. Proc Nat Academy Scie USA. 2009;106(21):866570.

36. Casuso RA, Plaza-Díaz J, Ruiz-Ojeda FJ, Aragón-Vela J, Nikolai BN, Jesus RH. High-intensity high-volume swimming induces more robust signaling through PGC- $1 \alpha$ and AMPK activation than sprint interval swimming in triceps brachii. Plos One. 2017;12(10):e0185494.

37. Wadley AJ, Chen YW, Lip GY, Fisher JP, Aldred S. Low volume-high intensity interval exercise elicits antioxidant and anti-inflammatory effects in humans. J Sports Sci. 2016;34:1-9.

38. Rovqani DF, Rovqani M, Balouch-nezhad MT. Effects of curcumin on serum levels of Aspartate and alanine aminotransferase enzymes and oxidative stress indices within heart tissue of diabetic rats. J Shahid-Behesti Med Scie. 2012;17;1(85):2-18.

39. Freitas DA, Rocha-Vieira E, Soares BA, Nonato LF, Fonseca SR, Leite HR. High-intensity interval training modulates hippocampal oxidative stress, BDNF, and inflammatory mediators in rats. Physiol Behav. 2017;184:611.

40. Tauler P, Aguiló A, Gimeno I, Fuentespina E, Tur J, Pons A. Response of blood cell antioxidant enzyme defences to anti- oxidant diet supplementation and intense exercise. Eur $\mathrm{J}$ Nutr. 2006;45, 187-95.

41. Ramis TZ, Medeiros NS, Muller CHL, Boeno F, Silveira D, Souza LG, et al. Effects of Acute Exercise with Blood Flow Restriction on Oxidative Stress Biomarkers. Intern J Sports Scie. 2017;7(5):191-95.

42. Ezraty B, Gennaris A, Barras F, Collet JF. Oxidative stress, protein damage, and repair in bacteria. Nat Rev Microbiol. 2017;15(7):385-96

43. De Araujo GG, Papoti M, Dos Reis IG, de Mello MA, Gobatto CA. Physiological responses during linear periodized training in rats. Eur J Appl Physiol. 2012;112:839-52.

44. De Araujo GG, Papoti M, dos Reis IGM, de Mello MAR, Gobatto CA. Short and Long-Term Effects of High-Intensity Interval Training on Hormones, Metabolites, Antioxidant System, Glycogen Concentration, and Aerobic Performance Adaptations in Rats. Front Physiol. 2016; 7:505.

45. Ji LL. Modulation of skeletal muscle antioxidant defense by exercise: role of redox signaling. Free Rad Biol Med. 2008;44(2):142-52.

46. Azizbeigi K, Azarbayjani MA, Peeri M, Agha-Alinejad H, Stannard S. The effect of progressive resistance training on oxidative stress and antioxidant enzyme activity in erythrocytes in untrained men. Int J Sport Nut Exercise Met. 2013;23(3): 230-38.

47. Songstad NT, Kaspersen KH, Hafstad AD, Basnet P, Ytrehus K, Acharya G. Effects of High-Intensity Interval Training on Pregnant Rats, and the Placenta, Heart, and Liver of Their Fetuses. PLoS One. 2015; 10:e0143095.

\section{Corresponding author}

Lúcio Marques Vieira Souza. Federal University of Sergipe, Department of Physiology - Laboratory of Natural Products Chemistry and Biochemistry. Cidade Universitária Prof. José Aloísio de Campos. Marechal Rondon Avenue, s/n Jardim Rosa Elze. 49100-000 - São Cristóvão/SE, Brazil. Telephone: +55 (79) 3194-6453. E-mail: profedf.luciomarkes@gmail.com.

Manuscript received on November 27, 2020

Manuscript accepted on January 2, 2021

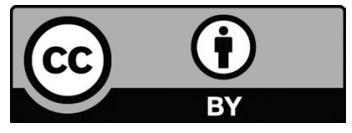

Motriz. The Journal of Physical Education. UNESP. Rio Claro, SP, Brazil - eISSN: 1980-6574 - under a license Creative Commons - Version 4.0 